\title{
Griffith University
}

\section{Nigel Krauth}

\section{The story in my foot: writing and the body}

\begin{abstract}
Where do stories reside? Where do we find them to tell them from? Where should the writer focus the search for stories to fuel an output of poetry or fiction? Traditionally, the creative writing process is thought to involve reading the world as a text, reading actual texts, and 'reading' the memory or the imagination. But, following Merleau-Ponty (1945), recent studies of experience and the body by Yuasa (1987), Varela et al (1991), Grosz (1994), Clark (1998) and Gallagher (2006) suggest there may be another repository for story: the body itself beyond the brain. Surprising anecdotal evidence suggests that in some human-parts transplants, memories are transplanted too. This paper investigates aspects of the idea that stories are lodged in our whole bodies, and reviews some classroom exercises employing the concept of cellular memory.
\end{abstract}

\section{Introduction: electricity and the body}

In 'Song of Myself' Walt Whitman catalogues the world, and claims he contains it. He asserts he is 'a kosmos'; that his body 'is no callous shell' but has 'instant conductors all over' which 'seize every object and lead it harmlessly through' him. Of pleasures he says, 'I graft and increase [them] upon myself'; of pains, 'I translate [them] into a new tongue.' He concludes: 'I am an acme of things accomplished ... an encloser of things to be' (Whitman 1986: 11.422-5, 613-5, 1148).

Whitman's grand project of recording and retaining the world in and through himself - in fact, in and through his whole body, because he confesses he is 'mad' for the world to be 'in contact' while he is 'undisguised and naked' (1.12) is a starting point for my setting out to find experience and stories in parts of my own body other than my brain.

Lawrence Hass uses Whitman to explain Merleau-Ponty's philosophy of living embodiment. Indicating problems surrounding Descartes' longstanding mindbody split, Hass stresses Merleau-Ponty's contention that while ever we think of the body as 'an inanimate object constructed of independent systems [i.e. independent from the mind] ... we will never understand its life' (Hass 2008: 75; emphasis in original). According to Merleau-Ponty and Hass, the consequence of Descartes is that we will forever be 'out of step' with our bodily experience; we'll be 'dislocated' from how we orient ourselves in the world; and we'll remain 'unaware' of the real nature of things because scientific models to 
which our culture is wedded don't allow us to contemplate experience in more fruitful and realistic ways (Hass 2008: 75). Hass emphasizes that MerleauPonty's philosophy 'requires that we celebrate embodied experience and not despise it: that we learn, with Whitman, how to "sing the body electric"' (Hass 2008: 75; emphasis in original).

I have often wondered why Whitman's body was 'electric' - why he felt it thus in 1867 when he added the title to his already-published poem, when electricity was still a scientific curiosity. In Whitman's time, primitive electric motors had not emerged from experimenters' benches; there was no distribution of electricity in cities; and the invention of the commercial light bulb was still some years away. Electricity did nothing of cultural significance in his day; it was not an applied source of power. What did he think he was saying? One presumes he had the concept of 'the charge' familiar in lightning and in human activity producing static electricity: Benjamin Franklin's experiments with kites and thunderclouds, and Joseph Priestley's book History and present status of electricity (1768) had been known for a century. But Whitman's concept of electricity, reflecting his time's relative ignorance, was nature-oriented and almost entirely speculative as regards its mechanical applications. Judging from the poems Whitman produced - i.e. the 'singing' he did, especially Leaves of grass with its vast, inclusive human scale, its universal embrace, its multitudinous storytelling - he had a powerful sense of electricity in his body being a sort of narrative and genealogical charge.

We now know that electricity in the body equates with life itself. The body operates in living moments by the electricity it produces (see any HowStuffWorks-type scientific website for an explanation of this, e.g. Layton 2008). I have electrocuted myself twice in my life and know the feeling of too much electricity in the body; I can reproduce in memory the trauma of its ballooning, lethal rush. And in recalling those potentially fatal electrocutions, my body participates with a panicky body-memory response. At the other end of the voltmeter, I have also speculated that couples might be matched according to their respective body charges - Touch a prospective lover and analyze the feeling before you commit! Thus I have, in a folksy way, decided that 'the body electric' is a significant concept; at a personal level it deals with notions of life, death and love.

I remember at university writing a primitive poem about the memory of sex lingering with me as electricity in my body. Inspirational Whitman wrote, recalling past lovers:

My lovers suffocate me!

Crowding my lips, and thick in the pores of my skin ... (1986: 11.1170-1)

I still agree with Whitman. Experience takes up occupancy in parts of our bodies other than the brain. Memory does not reside solely in the head.

\section{The residence of memory: reflection and experience}

The surface of the body is recognized as a memorial site for cultural productions. Elizabeth Grosz discusses the use of the skin as inscriptive surface in primitive and contemporary societies. She notes that incised 'welts, scars, cuts, tattoos, perforations, incisions, inlays ... [create] places of special significance and libidinal intensity' (Grosz 1994: 139), and that 'the intensity and flux of the sensations traversing the body become fixed into consumable, gratifiable needs and desires' (Grosz 1994: 139). She talks about diet and 
bodybuilding too as inscriptions on the body, and concludes that 'in feminist terms at least, it is problematic to see the body as a blank, passive page, a neutral "medium" or signifier for the inscription of a text' (Grosz 1994: 156). Grosz insists that texts written by experience on the surface of the body have personal, as well as cultural, significance (Grosz 1994: 155-6).

There are also indicators regarding sites for memory and creative production deeper in the body in what creative writers say about 'sourcing' their processes and where creative ideas come from. In the following quotations, where writers candidly describe their processes, their metaphors reveal a significant sense of the body as production site. Some, such as Germaine Greer and Charles Bukowski, place the source of writing in their bowels, and by doing so reinforce the idea that writing is in part a process operated by automatic body functions:

[Writing is] a bit like shitting ... if it's coming in dribs and drabs or not coming at all, or being forced out, or if you're missing the rhythm, it's no pleasure at all. (Greer in Winokur 2000: 107)

Don't ever write a novel unless it hurts like a hot turd coming out. (Bukowski in Winokur 2000: 107)

Jack Kerouac identified his process as convulsion, a body function beyond his writerly control:

What a man most wishes to hide, revise and un-say, is precisely what Literature is waiting and bleeding for - Every doctor knows, every Prophet knows the convulsion of truth. (Kerouac in Winokur 2000: 106)

Rebecca West situated her memory, an inspiration for her writing, in her hands:

My memory is certainly in my hands. I can remember things only if I have a pencil and I can write with it and I can play with it. I think your hand concentrates for you. (West in Plimpton 1992: 64)

Classic cases of the writer's relationship with memory are expressed by Eudora Welty and Henry James:

It's like sending a bucket down a well and it always comes up full ... I guess you're tuned in for it, and the right things are sort of magnetized ... (Welty in Plimpton 1992: 212)

The great thing is to be saturated with something - that is, in one way or another, with life ... (James 1972: 63)

In each of these accounts, there is a sense that the writing process is located, partly or wholly, somewhere in the body beyond the brain. But exactly where is not easily identified. In the best circumstances (those of Welty and James), you ask of your body and you receive. With Greer and Bukowski, you continue to strain and the body ultimately provides. With Kerouac and West, you wait for the convulsion to happen, or find a clever way to prompt it.

Science currently situates memory in the brain (for two classic studies of this, see Kandel 2007 and Rose 2003) and acknowledges that memory is cellular, i.e. memory is contained in the brain's neurons, or nerve cells (see e.g. Kandel 2007: 53ff). Alongside this, cognitive biologists and philosophers suggest 
memory resides elsewhere too (see e.g. Varela et al 1993: 27ff). Various studies from 1883 onwards discuss 'muscle-memory' or 'motor memory' (see e.g. Morris 2009 [1883]; Varela et al 1993: 28-9), accounting for how dancers, musicians and athletes remember highly complex sequences in their practice. Akin to this is our ability as ordinary individuals to take up again a skill we thought we had lost. We can get back onto a bicycle after many years of cycling inactivity; we can pick up a guitar and play that old chord progression we used to love. It seems that muscles hold memory alongside the brain.

In The Embodied Mind (1993), Varela, Thompson and Rosch seek to bridge gaps between cognitive science and human experience, and between western and eastern philosophies. They hold with Merleau-Ponty that we need to see our bodies 'as both physical structures and as lived, experiential structures' with a continuous circulation between the "'outer" and "inner", [the] biological and phenomenological' (Varela et al 1993: xv):

Body and mind can be brought together. We can develop habits in which body and mind are fully coordinated. The result is a mastery that is not only known to the individual meditator himself but that is visible to others - we easily recognize by its precision and grace a gesture that is animated by full awareness. We typically associate such mindfulness with the actions of an expert such as an athlete or musician. (Varela et al 1993: 28, emphasis added)

Japanese philosopher Yuasa Yasuo calls this full awareness, 'cultivation':

Personal 'cultivation' (shugyõ) is presupposed in the philosophical foundation of the Eastern theories. To put it simply, true knowledge cannot be obtained simply by means of theoretical thinking, but only through 'bodily recognition or realization' (tainin or taitoku), that is, through the utilization of one's total mind and body. Simply stated, this is to 'learn with the body', not the brain. Cultivation is a practice that attempts, so to speak, to achieve true knowledge by means of one's total mind and body. (Yuasa 1987: 25-26)

Of further interest to writers, is Yuasa's development of notions of 'bright consciousness' and 'dark consciousness'. The former concerns the articulate, everyday thinking the mind seems to do on its own, e.g. the cogito, which has been the preoccupation of western philosophy since Descartes. In dark consciousness, however, Yuasa suggests, 'the mind-body acts of itself, creatively and spontaneously, without explicit awareness of the what, why and how'. This is not to be confused with Freud's subconscious: although there are similarities: 'dark consciousness is a positive source of creativity, inspiration, and intellectual insight' (Kasulis in Yuasa 1987: 33).

The line of argument followed by Merleau-Ponty, Yuasa and Varela suggests that experience utilizes, and distributes its traces, through a complex of mindbody sites and pathways. In the process of reflection - a re-contacting of experience - these sites and pathways are re-traced in a manner similar to that discernible in muscle-memory. When we get back onto that bike or pick up that guitar after many years and still know how to use it, we are calling on our bodies to remember. Eastern philosophies suggest that the body stores memories in more sites than merely its muscles - muscle-memory exists alongside full body-memory. 
Whitman called attention to inspirational electricity in our bodies. Cognitive philosophy and eastern theories suggest the body has multiple sites for experiential record. Perhaps what writers have called 'the Muse' and other visitational manifestations, in fact reference experience captured in accessible memory banks in our bodies. Informed by experience already gained, by nervous and muscular system histories, by vestiges of narratives that have passed via our senses through our bodies to our brains previously, it seems there are parts of our bodies ignored as real sources of writing.

\section{Writing and the body}

Very young writers go looking for stories in their imaginations. Perhaps due to a lack of understanding of their experience, they think they have to make things up. Older writers tend to a more ambiguous relationship with their imaginations. They seek their stories in real experience, then apply imagination as a shaping and gluing device. Mature writers in fiction and poetry re-fashion their pasts, collage the facts from across much experience, and fictionalize from the known.

In other words, the writer's relationship with his/her source material is a moveable feast. Age, maturity and capacity to handle imagination are key factors. In each of these areas, memory is operative. But there are writers who are aware of places other than brain-memory, including their own bodies, as the sources of writing. The boundaries of the mind are not necessarily the boundary for finding personal stories.

Writing in the 21st century isn't the same as it was for writing in times past. Greek and Roman writers found stories in the mythological environment, which was for them religion and history and nature combined. There was a sense, derived from oral traditions, that re-telling anew an old story, with the writer's added particular flair, was the valued role of the writer. If you needed a story, you searched the myths and traditions of storytelling. This Classical attitude lasted until the Middle Ages (and had a resurgence in the 18th century, as also in recent postmodern times). By this method, writing entails a trawl through the already-told. It is a function of collective/social memory, gathered in the brain. But, as Homer and other remembered classical writers have shown, the re-inhabiting of an old story best involves an entwining of the contemporary brain and body into the narrative.

The first great work of writing in English is Chaucer's Canterbury tales. Significantly it is about a group of walkers and riders - pilgrims heading from London towards Canterbury cathedral. Chaucer's narrative focuses on 24 storytellers; they tell their stories as they walk. Several of the tales are based on stories in circulation in the oral tradition of the time, and also available to the educated in manuscript form. For example, Boccaccio's Decameron seemingly provided the source for six of the Tales (Kolve \& Olson 1989: 235). But Chaucer's 14th century brilliance lay in his telling new tales while newly framing others. This revolution - where the writer tells his or her own stories based on a journey - continued to develop until the major Romantic revolution in the early 19th century where Wordsworth, Coleridge, Thoreau and Baudelaire went on self-imposed treks through the environment seeking purposefully to gain individual experience to write about.

The Romantic writers didn't sit, confronted by a blank page, and think about what they might write: they trekked out into the world and made something happen to write about. Seeing writing as a collecting of perceptions and 
attempts at understanding, as a gathering-in of experience, they sallied forth and sought the harvest. If writing was a test, they were their own test-crash dummies. They climbed the French Alps, walked the English Lake District, tramped Massachusetts and sidled the arcades of Paris, determinedly seeking inspirational material.

I wandered lonely as a cloud

That floats on high o'er vales and hills,

When all at once I saw a crowd,

A host, of golden daffodils ... (Wordsworth 2002)

Wordsworth's 'Daffodils' is a poem about the writer experiencing his environment - about not sitting and waiting for inspiration, but going and getting it, then mulling it over. The poem was not an accident of wandering. The writer walked as a professional activity, with the aim of producing culturally significant writing (see Solnit 2000: chapters 6-7).

The key concept here involves the writer putting her/his body on the line. Plenty of writers have done this. Of Henry Thoreau, American nature writer, Ralph Waldo Emerson wrote:

[Regarding walking] He said he wanted every stride his legs made. The length of his walk uniformly made the length of his writing. If shut up in the house, he did not write at all. (Emerson 2008 [1863]: 12)

Thoreau gathered information bodily. Thoreau himself wrote about Wordsworth:

When a traveller [visiting the poet's house] asked Wordsworth's servant to show him her master's study, she answered, 'Here is his library, but his study is out of doors.' (Thoreau 2008 [1863]: 98)

Thoreau wrote: 'In my walks I would fain return to my senses' (Thoreau 2008: 99), and by this he directs us not to the common-sensical, as is the current meaning of 'to return to one's senses', but to the real meaning of the phrase: that is, a return to the five actual senses of seeing, hearing, tasting, touching and smelling. As Irish poet WB Yeats said: 'Art bids us touch and taste and hear and see the world ...' (Yeats 1985: 107). Writing is a business of moving through the world, through our cultures, among the people, the behaviours, the thinking there, and sampling, reviewing, assessing, celebrating, and further seeking. Writing isn't merely settling down at a desk and contemplating. Writing is reading the text of the world and re-telling it in your own unique, perceptive way.

Charles Baudelaire did this. He walked the streets and arcades of Paris circa 1845. He was the first flâneur, or stealth observer. Famously he recorded sex, death and pink bits in Paris. He was like the barely-noticed dog in the alleyways, sniffing at rotten rubbish cans. As a writer who insistently focused on the sexy, the ugly, the gross underground stink of Paris - and did so in gorgeous, literary writing - he brought upon himself considerable criticism. Also, of course, he did much to define the nature of French culture as we know it:

City of swarming, city full of dreams

Where ghosts in daylight tug the stroller's sleeve!

Mysteries everywhere run like the sap 
That fills this great colossus' conduits. ('The seven old men' Baudelaire 1993: 177)

Travelling the metaphoric arteries and nervous system of Paris, Baudelaire doesn't find things explicable except in the most hellish terms. In this cityscape he doesn't see daffodils, but instead a host of reminders that his soul is exiled from its stay on earth. Baudelaire reacts bodily to Paris street scenes:

I turned my back on this parade from Hell.

Bedazzled, like a double-visioned drunk, I staggered home and shut the door, aghast, Shaking and sick ... (Baudelaire 'The seven old men' 1993: 181)

Wordsworth went home, lay down on his couch, and pleasurably recreated his walking experience; Baudelaire went home, slammed his door, and unsuccessfully tried to eradicate the experience from his system.

Actually, I love walking in Paris, as I love walking in Labrador on the Gold Coast (where I live) and Sydney, London, New York, Barcelona, Athens, Isle of Capri, Corfu, Ithaca - where I have also had the opportunity to stay on occasions. I love walking to get in touch with the world and find stories. It fits with the idea of any piece of writing being a journey for writer and reader both. The most-often used paradigm for storytelling is that of a journey, a movement through spaces. As writer - as also for the reader - I set out, I don't necessarily know where I am going or what I will experience along the way, I take the journey, I get to the end, and I find that time and space are subtly or dramatically shifted for me. That's story!

In most stories characters are shifted, they move from setting to setting; they move from ignorance to experience. As reader you are shifted too - the process of reading and learning is one of being transferred from understanding to new understanding. It was true for Chaucer's Canterbury's tales and for Swift's Gulliver's travels as it is also true for Star wars and The da Vinci code. The idea of a physical journey is paralleled in a psychological journey for the characters involved, and their journey is replicated for the reader. Poems and stories are shifting mechanisms, are journeys of upheaval from a place left behind into new experience, new vision, new knowledge and understanding. But clearly, this shifting, recording and re-interpreting doesn't occur exclusively to either the body or the mind, for the writer. Writers who find significance in new physical experience are responding with their whole body.

Merleau-Ponty situates thinking not just in the brain, but in the entire body. $\mathrm{He}$ says:

My body is the fabric into which all objects are woven, and it is, at least in relation to the perceived world, the general instrument of my 'comprehension'. (Merleau-Ponty 2005: 273)

Even more poetically, he goes on to say:

my body is made of the same flesh as the world ..., and moreover ... this flesh of my body is shared by the world, the world reflects it, encroaches upon it and it encroaches upon the world ... they are in a relation of transgression or of overlapping - This also means: my body is not only one perceived / among others, it is the measurant ... of all the dimensions of the world. (Merleau-Ponty 1969: 248-49) 
In other words, Merleau-Ponty says he perceives his body as if it is the external world, and at the same time it is his body, a thinking and measuring device. Baudelaire, Wordsworth and Thoreau would agree.

\section{My and others' bodies, and writing}

Last month I had a colonoscopy, and I was disappointed. I had a general anaesthetic; I had to be unconscious during the process. Thus my specialist knows more about the journey to the centre of my colon than I do. I'm pissed off. Why should someone $I$ pay do a scenic tour of my bowels and find out more about my internal environment than I know? What stories does my surgeon tell his friends at dinner parties about my colon? What fantastic voyages might I describe if I could see myself from the inside?

But if I can't walk through my own body, perhaps I can walk around and across it. I'm reminded of Jonathan Swift's Gulliver's travels, where the Lilliputians have Gulliver roped down and they're swarming over him: little men all over a big man. I'd like to be one of those Lilliputians, a Lilliputian writer, in fact, and I'd like the roped-down body to be my own. I'd like to walk in miniature all over me, to take my time, and examine me. 'Good morning, folks. I'm Nigel and I'm currently traversing the slopes of Nigel's body. I'm looking for stories... Ahh! I think I've just seen one...' I like the idea of searching for stories across and around me, seeking where they are attached to me.

The first thing I'd notice is that I have a lot of moles. If I were walking in Wordsworth's Lake District, I'd remark on this straight away.

I wandered lonely as a cloud

That floats on high o'er vales and knolls,

When all at once I saw a crowd,

A host, of blackish, fucking moles ...

I don't like my moles, in case you were wondering. Here, for example, my body stores stories for me. I'm still coming to terms with the mole-stories my body keeps telling me. They involve teenage insecurities, crises of identity, lack of love of self, and so on. Through them my body defines me.

A new perspective has emerged recently. Websites, but not yet medical science, are saying that memories exist in body-parts. People who have undergone transplants are getting memories from the donors:

A 29-year-old lesbian, who was a fast food junkie, received a heart from a 19-year-old 'man crazy' vegetarian woman. After her operation, she found that she could no longer eat meat, as it made her sick. More strikingly, her sexual orientation completely changed and she became engaged to a man. (Hayes 2008)

Or:

A former professional dancer, in 1988 Claire Sylvie received a heart and lung transplant after suffering from Primary Pulmonary Hypertension. After the operation, she developed a taste for beer, Snickers bars, green peppers and fried chicken, none of which she had liked prior to the operation. She lost her attraction to men, and her daughter noticed that she had developed a masculine demeanour and walk. She began to have 
dreams of talking to a tall thin man with sandy coloured hair called Tim, whom she felt close to. After investigation through the hospital administration, she discovered that the heart and lung donor was an 18-year-old man named Tim, who had been killed in a motorcycle accident. After contacting his family, she discovered he'd loved beer, Snickers and fried chicken. (Hayes 2008)

Medical science, while sceptical of the affidavits of people with transplants, categorise this syndrome under cellular memory. Anecdotal evidence suggests memories can be passed on with parts of the body. So, if experience might be recorded not just in our brain, but in all our bits, then as writers we should go searching for them.

When I was eleven years old I was newly promoted from the Cubs to the Boy Scouts. This meant I could go away on Scout camps. For Christmas that year, my parents gave me the gift of a tomahawk - a small axe - something I had begged them for. Having this in my haversack would give me Scout-camp cred. I'd be totally cool in front of my peers as I hacked down a sapling to make a tent pole. I took my new gift from under the Christmas tree and immediately went outside, hauled a thin eucalypt stem to the ground, put my foot on it to counteract its springiness, and slashed a swathe into my foot. The upshot of the tomahawk Christmas present was a gaping wound, nauseating white bones exposed, a rush to hospital in the neighbour's car, and a foot full of Christmasday stitches.

I thought recently to use this story in a fiction written either for children or adults. When attempting to recall the moment of the impact, I found that my foot - the still-scarred one - would tingle, would call attention to itself, would make itself present in my brain as the source of the memory. I sought to test the phenomenon. I tried to think about the Christmas tomahawk event without involving my foot's response. It didn't work. My foot pulsated the memories. So I tried to see if I could remember the event without involving my brain. It did work. I could go straight to my foot - not think about it as a foot but somehow contact it directly without thinking. I began to realise that the story of my hacking my foot resided in my foot, not in my brain. My brain will call on my foot to tell the story. My brain-memory isn't that story's storehouse, it's merely the intermediary; it's just the controller flicking the switch. The repository for the story is my foot itself.

\section{Conclusion: the body and writing exercised}

In his how-to-write book, Writing from the body (1994), John Lee says: 'The body is home to all that has happened to us, and it remembers' (Lee 1994: 17). He says: 'To embrace our body's truth is to embrace our past'. He insists that 'people who live in their bodies, who aren't just visitors in their own skins' (Lee 1994: 17, 23) have a significant advantage as writers.

Lee's advice follows that of an earlier how-to-write book, Natalie Goldberg's US bestseller, Writing down the bones, originally published in 1986. Inspired by eastern theories, Goldberg made statements such as:

I am trying to come alive, to find the distances in my own recesses and bring them forward and give them color and form.

(Goldberg 2005: 124) 
Give yourself tremendous space to wander in, to be utterly lost with no name, and then come back and speak. (Goldberg 2005: 139)

Watching your breath, being present with your whole body, is the medium of the zendo. Words are the medium, of writing. When your words are alive, they are electric beings - they are not one jot removed or distant from human life. (Goldberg 2005: 187)

I have used exercises based on writing the body in my third-year undergraduate creative writing classes. I have suggested that students locate stories in parts of their anatomy. I have suggested they structure pieces into sections by thinking around the body - the eyes, the mouth, the hand, the thigh. The results have been excellent. By focusing on their body parts, students find stories I firmly believe they would not otherwise contact. And they report, as I myself have found, that the process involves not just brain-memory, but body-memory. Goldberg provides a useful supporting statement for such exercises:

you have topics you want to write about ... but come to it not with your mind and ideas, but with your whole body - your heart and gut and arms. Begin to write in the dumb, awkward way an animal cries out in pain, and there you will find your intelligence, your words, your voice. (Goldberg 2005: 40)

Writers search for stories in the imagination, the environment, and the traditionally-understood memory. These are perfectly good places to go looking. But have a thought also for looking around the body - from outside and inside - and concentrating. Writing is reading the text of the world and retelling it. Our memories, imaginations and bodies are part of that reading of the world. We carry in us more stories than we know.

\section{List of works cited}

Baudelaire, C 1993 The flowers of evil (trans J McGowan), Oxford: Oxford University Press return to text

Emerson, RW 2008 [1863] 'Biographical sketch' in HD Thoreau, Excursions, Rockville MA: ARC Manor, 7-23 return to text

Goldberg, N 2005 Writing down the bones: freeing the writer within, Boston MA: Shambhala return to text

Grosz, E 1994 Volatile bodies: toward a corporeal feminism, Bloomington and Indianapolis: Indiana University Press return to text

Hass, L 2008 Merleau-Ponty's philosophy, Bloomington and Indianapolis: Indiana University Press return to text

Hayes, S 2008 'A medical mystery: transferred organ donor consciousness', Scienceray (August 12): http://scienceray.com/philosophy-of-science/a-medical-mystery-transferred-organ-donorconsciousness/ (accessed 24 August 2009) return to text

James, H 1972 Theory of fiction (ed JE Miller), Lincoln NE: University of Nebraska Press return to text

Kandel, ER 2007 [2006] In search of memory: the emergence of a new science of mind, New York: WW Norton return to text 
Kolve, VA \& G Olson 1989 The Canterbury Tales: Nine Tales and the General Prologue, New York: WW Norton return to text

Layton, J 2008 'How does the body make electricity - and how does it use it?' HowStuffWorks http://health.howstuffworks.com/human-body-make-electricity.htm (accessed 12 March 2010) return to text

Lee, J 1994 Writing from the body, New York: St Martin's Press return to text

Merleau-Ponty, M 2005 [1945] Phenomenology of perception (trans C Smith), London: Routledge return to text

Merleau-Ponty, M 1969 [1964] The visible and the invisible (trans A Lingis), Evanston IL: Northwestern University Press return to text

Morris, MA 2009 [1883] The book of health, Newcastle upon Tyne: Cambridge Scholars Publishing return to text

Plimpton, G (ed) 1992 The writer's chapbook, New York: Penguin return to text

Priestley, J 1768 The history and present status of electricity, with original experiments, London: Dodsley, Johnson, Davenport \& Cadell return to text

Rose, S 2003 [1992] The making of memory: from molecules to mind, London: Vintage return to text

Solnit, R 2000 Wanderlust: A history of walking, New York: Penguin return to text

Thoreau, HD 2008 [1863] Excursions, Rockville MA: ARC Manor return to text

Varela, FJ, E Thompson and E Rosch 1993 [1991] The embodied mind: cognitive science and human experience, Cambridge MA: MIT Press return to text

Whitman, W 1986 [1855] Leaves of grass: the first (1855) edition (ed Malcolm Cowley), New York: Penguin return to text

Winokur, J (ed) 2000 Advice to writers, London: Pavilion return to text

Wordsworth, W 2002 [1807] 'I wandered lonely as a cloud' [from Poems in two volumes 1807] Representative poetry online University of Toronto Press:

https://tspace.library.utoronto.ca/html/1807/4350/poem2337.html (accessed 16 November 2007) return to text

Yeats, WB 1985 [1912] 'Three pieces on the creative process: the thinking of the body', in Brewster Ghiselin (ed) The creative process: reflections on invention in the arts and sciences, Berkeley CA: University of California Press, 106-07 return to text

Yuasa, Y 1987 The body: towards an Eastern mind-body theory (ed TP Kasulis, trans N Shigenori and TP Kasulis), Albany NY: SUNY Press return to text

Keywords: writing process; writing and the body; memory

Associate Professor Nigel Krauth teaches writing at Griffith University, Gold Coast. With Jen Webb he is co-editor of TEXT: Journal of Writing and Writing Programs www.textjournal.com.au <http://www.textjournal.com.au> and with Tess Brady is co-editor of Creative Writing: theory beyond practice (Post Pressed 2006). Tess and Nigel's latest collaboration is The Clunes little book of the book (Clunes Arts Press 2010). 
TEXT

Vol 14 No 1 April 2010

http://www.textjournal.com.au

Editors: Nigel Krauth \& Jen Webb

Text@griffith.edu.au 